\title{
VIEWING HABITS AND IDENTIFICATION WITH TELEVISION CHARACTERS AMONG AT-RISK AND NORMATIVE CHILDREN AND ADOLESCENTS
}

\author{
Gila Cohen Zilka and Shlomo Romi
}

\begin{abstract}
This study examined the relationship between participants' negative or positive identification with television characters and their behavior, and how their reactions in times of anger - whether simply negative or physically violent varied between at-risk participants and normative ones. Participants were 86 children and adolescents from Israel who filled in four questionnaires on the topics of viewing habits, attitudes, self-image, and aggression. The findings revealed that at-risk children and adolescents reacted with more anger than did their normative counterparts, and that their reaction became stronger when they identified with a character's negative behavior. It was further revealed that the more they watched, the higher their identification with the character and the greater their negative reaction during anger. A violent physical reaction in times of anger is more strongly associated with viewing alone than with viewing with friends. The findings also revealed that identification with the character is a mediating variable between the amount and type (solitary or with friends) of viewing and negative and violent reactions. At-risk children and adolescents tend to choose programs that show violent behaviors, and such programs could ultimately lead them to exhibit violent reactions. The question is how can the amount of children and adolescents' viewing be limited while avoiding arguments and punishment? The key to success is finding a solution that will be formulated with the children and adolescents' full cooperation.
\end{abstract}

Keywords: at-risk children, viewing habits, TV programs, identification, wellbeing, television characters

Gila Cohen Zilka PhD (the corresponding author) is Director of the Department for Teaching Social Science, Sociology and Communication at Bar-Ilan University, Achva Academic College, Ramat-Gan, 5290002 Israel. Email: gila.zilka@ gmail.com

Shlomo Romi PhD is Head of the Institute for Education and Community Research, School of Education, Bar-Ilan University, Ramat-Gan, 5290002 Israel. Email: Shlomo.Romi@ biu.ac.il 
International Journal of Child, Youth and Family Studies (2018) 9(3): 47-67

This comparison of at-risk and normative youth examined the relationship between viewing habits and identification with TV characters, and the relationship between negative or positive identification and the participants' characteristic reactions when angry, either simply negative or physically violent. The basis for the examination was uses and gratifications theory (UGT; Leung. 2013; McQuail, 2010; West \& Turner, 2007), which makes the underlying assumption that children and adolescents are consumers who choose from an available selection. This approach recognizes the viewer's power to choose what and when to watch. A guiding principle in UGT is that viewers selectively expose themselves to media, and this exposure is motivated by the needs they want to satisfy. UGT is the basis for many research studies around the world.

Four categories of needs motivate the choice of medium and viewing content (Leung, 2013; McQuail, 2010; West \& Turner, 2007):

1. Cognitive needs: needing to strengthen knowledge and comprehension.

2. Affective needs: needing to strengthen emotional experience, enjoyment, and aesthetic experience.

3. Integrative needs: needs relating to strengthening trust, confidence, stability, and status, as well as needing to strengthen ties with family, friends, and others.

4. Escapist needs: needing to break away from the physical environment and escape to "a different reality".

\section{Review of the Literature}

Recent studies conducted in Europe, the United States, and many other places around the world (Comstock \& Scharrer, 2007; Livingstone, 2007, 2009; Millwood Hargrave, 2007; Millwood Hargrave \& Livingstone, 2009; Zilka, 2014, 2016, 2017a) have shown that children and adolescents prefer TV to other forms of media, logging over 15 hours a week of viewing time on average. Therefore, in order to understand the day-to-day behavior of children, whether at risk or normative, it is important to clarify, examine, and compare viewing habits, so that adults can use an informed approach to the issue of TV viewing and better understand the factors involved.

UGT served as the lens through which the viewing habits of children and adolescents were examined. According to UGT (Leung. 2013; McQuail, 2010; West \& Turner, 2007):

1. Individuals choose which medium (internet or TV) they will watch, in addition to choosing the programs and the time spent watching. It is the individuals' needs that dictate the mode of exposure, the preferred medium, the degree of exposure, and the choice of content, a choice made from the selection offered. For example, children and adolescents may choose 
International Journal of Child, Youth and Family Studies (2018) 9(3): 47-67

— in accordance with their needs — to watch an action movie, a soap opera, or a variety show.

2. Individuals' needs change and are affected by intrapersonal and interpersonal factors as well as by environmental ones such as fatigue, stress, social circumstances, time of viewing, the time a program is broadcast, and the day of the week.

3. Individuals choose how they will spend their leisure. TV programs, whether seen on TV or online, provide one way of spending free time. At times, people may choose alternative ways to spend their free time; these ways must meet their needs.

4. To one degree or another, people can control their needs and decide how their needs are satisfied.

\section{Parasocial Interaction}

Children and adolescents have a need to understand the society in which they live: TV programs meet this need and serve as a supplemental socialization process. In the 1970s, researchers around the world became aware of this source of socialization and claimed that TV programs provide an extended family of sorts, one that represents a microcosm of society as a whole (Bandura, 1971, 1986; Nobel, 1976). Television programs are an arena where a child creates parasocial interaction with a large number of stable and transient characters.

The one-sided relationships that a viewer develops with TV characters are parasocial interactions. Viewers feel that they know the characters, and perceive that they have the same feelings toward them as they do toward flesh-and-blood acquaintances, but they are not worried that the TV character will criticize them (Bandura, 1971, 1986; Cole \& Leets, 1999; Hough \& Erwin, 2010; Livingston \& Das, 2010).

The attachments that children develop for TV characters are similar to the relationships children used to have as part of an extended family within a tribe or a clan (Cole \& Leets, 1999), but without concern over the possibility of criticism that could be embarrassing or even humiliating. Parasocial interactions, which can provide opportunities to examine "how to behave" in a variety of situations, play a similar role for children and adolescents as real social interactions. They provide essential social learning: how to react to the extended social group, how to integrate into society, and how to avoid certain situations. Although TV programs can present models for every social role, they do not provide consumers with a mirror image of themselves nor with the feedback necessary for total development (Morgan \& Shanahan, 2010; Rideout, Foehr, \& Roberts, 2010; Vandewater, Bickham, \& Lee, 2006; Wilson, 2011; Zilka, 2014).

Reality shows have been gaining popularity. Researchers (Coyne, Robinson, \& Nelson, 2010; Haridakis \& Rubin, 2009; Hough \& Erwin, 2010; Nelson, Springer, Nelson, \& Bean, 2008) have found that these programs, devoid of script, staging, and editing, are rife with aggression, gossip, tale-telling, exclusion, and social manipulation, to a much greater degree than prerecorded 
International Journal of Child, Youth and Family Studies (2018) 9(3): 47-67

programs. Research has revealed that children identify with the characters on reality shows and with their behavior. Children and adolescents whose TV viewing is unbalanced — watching for many hours, preferring to watch on their own without including parents or friends - could be harmed thereby (Conners-Burrow, McKelvey, \& Fussell, 2011).

Research has indicated that parents may be inclined to remove the TV or computer from their children's rooms or limit their viewing hours, but have difficulty proposing alternative activities; in addition, the children and adolescents perceive the time limitation and removal of the TV or computer as a punishment, creating a source of confrontation between them and their parents (Bybee, Robinson, \& Turow, 1982; Dorey et al., 2009; Epstein, Paluch, Kilanowski, \& Raynor, 2004; Jason \& Fries, 2004; Livingstone, 2009; Livingstone \& Das, 2010a, 2010b; Miller et al., 2007). Parents have reported fights and other difficulties, and that the children rejected the alternatives proposed (Dorey et al., 2009; Evans, Jordan, \& Horner, 2011; Jordan, Hersey, McDivitt, \& Heitzler, 2006). Not only are limits on viewing hours difficult to impose and a source of confrontation, they are often ineffective as the children and adolescents find a different medium or go elsewhere to watch the program (Jago et al., 2008; Jordan et al., 2006). This can create another problem: reality programs viewed online are not censored in any way, whereas there is some censorship when the same program is broadcast on TV.

As mentioned, children and adolescents prefer TV to other media (Livingstone, 2007, 2008; Millwood Hargrave \& Livingstone, 2006, 2009; Zilka, 2014, 2016). They spend more than 15 hours a week watching TV, increasing to over 17 hours for viewers aged 12 to 15 . Television is part of children's everyday environment, and plays a role in shaping their personalities in conjunction with other, interacting, environmental factors. Studies (Australian Communications and Media Authority, 2007; Alexander \& Hanson, 2003; Anderson \& Murphy, 2003; Bryant \& Zillman, 2002; Fowles, 2003; McQuail, 2010; Office of Commmunications, 2006, 2007, 2008; Potter, 2004) have shown that while a certain program affected one child, no effect was found on another, while yet another showed delayed effects. The degree to which a program will affect a child is determined by his or her needs.

The difficulties involved in limiting viewing have led researchers to suggest parents try different types of mediation model for children's viewing (Hancox, Milne, \& Poulton, 2004; Marshall, Biddle, Gorely, Cameron, \& Murdey, 2004; Zilka, 2014). Two such models are evaluative mediation and unfocused mediation (Bydee et al., 1982). In evaluative mediation, parents discuss the program with their children and talk about the characters, distinguishing between facts and interpretation, as well as between objective information and commercials. Parents using unfocused mediation will say something occasionally, but there is no dialogue between parent and child. The three types of mediation - limiting viewing, evaluative, and unfocused - have all been found to be only partially effective (Ableman \& Pettey, 1989; Valkenberg, Krcmar, Peeters, \& Marseille, 1999). Unfocused mediation is most frequently used; however, evaluative mediation — the least frequently used — is the most effective of the three (Bybee et al., 1982). 
International Journal of Child, Youth and Family Studies (2018) 9(3): 47-67

\section{At-Risk Children and Adolescents}

The definition of at-risk children used in this study is based on some 20 clauses from the 1989 United Nations Convention on the Rights of the Child, and on the report of the Schmidt Committee (2006). Both documents define at-risk children as those from birth to age 18 years who are living in situations in which they are in danger from their family or environment. Under these conditions, many of their basic rights for physical existence, health and development, and belonging to a family may not be upheld; nor may their rights to learn, acquire skills, enjoy personal health and well-being, belong to society and participate in it, and be protected from others and from their own behaviors. Among the conditions that may lead to a child being at risk are inadequate parental functioning, a parent's illness or death, neglect on the part of those responsible for the child, behavioral problems, problems of adjustment, financial difficulties, academic difficulties, social variance, immigration, belonging to a minority group, disability, transition from one setting to another, living in poverty, and living in a dangerous environment. The outcomes for children may include defective functioning in various areas, passivity, aggression, and even social deviance; moreover, children who have been exposed to neglect and abuse are at greater risk of developing mental disorders and have difficulty developing a healthy lifestyle (Ben Asher, Zionit, \& Kimchi, 2007; Grupper \& Romi, 2015, 2015; Harel, Molcho, \& Tilinger, 2003; Romi, 2001, 2007; Romi, Savicki, Grupper, \& Caspi, 2007; Zilka, 2015, 2017b).

The present study focuses on a comparison between at-risk children and adolescents and their normative peers regarding viewing habits, identification with TV characters, and day-to-day behavior. In addition, we compared the two groups as to viewing habits and reaction to the content viewed, and examined the association between viewing habits and identification with the TV characters, and that between negative or positive identification and negative and violent reactions in times of anger in both groups. Finally, and still comparing youth at risk to their normative peers, we went beyond the direct association to search for indirect associations between three factors identification with a TV character, amount of viewing, and viewing habits (alone or with friends) — and negative reactions and violent reactions.

\section{Method}

\section{Research Population}

The research population comprised 86 children and adolescents from Israel aged 9 to 18 . Of these, 32 were at-risk children and adolescents who were sampled in complementary facilities run by the Ministry of Welfare. These children had been in risk situations in their homes and environments, due to parental dysfunction, a parent's illness or death, child neglect, behavioral problems, adjustment problems, financial difficulties, academic difficulties, or transitions from one setting to another. The other 54 were normative adolescents attending regular state schools. 
International Journal of Child, Youth and Family Studies (2018) 9(3): 47-67

\section{Tools}

For this study, we used four research tools, which served to create representative measures through exploratory factor analysis with a Varimax orthogonal rotation.

Viewing habits questionnaire: This 50-item questionnaire has been in wide use among researchers around the world (Bybee et al., 1982; Van den Bulck \& Van den Bergh, 2000). Statements regarding parental mediation and viewing habits (solitary, with parents, or with friends) were rated on a 5-point Likert scale (1 - not at all, 5 - always; sample statement: "While we watch TV together, my parents talk to me about what I see.") The number of hours of viewing was listed from 1 hour to 7 hours or more (sample question: "On the average, how many hours a day do you watch TV on weekdays?"). The questionnaire yielded three 5-question measures for viewing habits:

1. Viewing habits and average number of viewing hours: 3.65 on a 5-point Likert scale, $S D=$ 1.12 , Cronbach's alpha reliability $=.85$.

2. Interactive viewing with friends: 2.34 on a 5-point Likert scale, $S D=0.89$, Cronbach's alpha reliability $=.97$.

3. Solitary viewing: 2.4 on a 5-point Likert scale, $S D=0.73$, Cronbach's alpha reliability $=$ .70 .

Attitudes toward identification with favorite characters: Statements on this 55-item questionnaire (Block, 1995) were rated on a 5-point Likert scale (1 - not at all, 5 - very much so; sample statement: When my favorite TV character is sad, so am I.). Two identification measures, suitable for this study, were chosen from this questionnaire:

1. Positive identification with the character measure: 18 items; $M=3.76, S D=1.07$, Cronbach's alpha reliability $=.93$.

2. Negative identification with the character's behavior: 22 items; $M=3.76$ (on a 6-point scale), $S D=1.25$, Cronbach's alpha reliability $=.97$.

Forms of aggression (FOA) questionnaire: This questionnaire (Verona, Sadeh, Case, Reed, \& Bhattacharjee, 2008) includes 40 self-report items about the participant's involvement in various forms of aggression when angry. Participants rated the frequency of their aggressive behavior on a 5-point scale (1 - never, 5-always; sample statement: When I'm upset with other people or angry with them I: Starting hitting / Physically threaten them). A factor analysis yielded two measures for propensity toward aggression:

1. Negative reaction: 17 items; $M=2.36, S D=0.91$, Cronbach's alpha reliability $=.97$.

2. Violent physical reaction: 23 items; $M=1.54, S D=0.78$, Cronbach's alpha reliability $=.96$. 
International Journal of Child, Youth and Family Studies (2018) 9(3): 47-67

Sociodemographic and socioeconomic questionnaire: This questionnaire included 16 self-report items, among them personal data, parents' marital status, parents' occupation, name of town of residence, number of people at home, and number of rooms at home. In addition, there was one question about the degree to which the participant was at risk, a question answered by the personal mentor of each participant.

\section{Procedure}

The children's parents were approached and were asked to give their consent to filling out the form. After the parents signed, the questionnaires were distributed, and each participant received an explanation of the questionnaire and how to fill it out. The children at risk filled in the questionnaires in the presence of their mentors in their therapeutic settings; the normative children, in the presence of an adult research assistant. It took an average of about 25 minutes to fill in the questionnaire.

\section{Results}

The $\chi^{2}$ tests conducted to examine differences in percentage of frequency of at-risk participants by demographic variables yielded the following statistically significant findings: $56 \%$ of the at-risk participants and $11 \%$ of the normative ones were children of divorced parents $(p<$ $.01)$. Participants in the at-risk group had low (43\%) and medium (48\%) academic achievement, whereas most of the participants $(62 \%)$ in the normative group had high achievement $(p<.01)$. At-risk participants were characterized by a low-medium level of behavior, as compared to high levels among the normative participants $(p<.01)$. The homes of at-risk participants had fewer rooms than those of their counterparts in the normative group $(p<.01)$. No significant differences were found between the groups in number of siblings and socioeconomic level of town of residence, but significant relationships were found between variables indicating the family's economic situation (parents' occupation, type of dwelling, and child's definition of financial status) and being at risk $(p<.01)$.

\section{Measures of TV Viewing and Reactions to Viewing: Comparing At-Risk and Normative Participants}

To examine differences among all research variables between at-risk participants and their normative counterparts, a MANOVA and an ANOVA were conducted. The differences between the groups in TV viewing and reactions to the viewing are presented in Table 1. 
International Journal of Child, Youth and Family Studies (2018) 9(3): 47-67

Table 1 Measures of TV Viewing and Reactions to Viewing: Differences between At-Risk and Normative Participants

\begin{tabular}{|c|c|c|c|c|c|c|c|c|}
\hline \multirow[b]{2}{*}{ Measure } & \multicolumn{2}{|c|}{$\begin{array}{l}\text { Normative } \\
\text { Participants } \\
\quad(n=54)\end{array}$} & \multicolumn{2}{|c|}{$\begin{array}{l}\text { At-risk Participants } \\
\qquad(n=32)\end{array}$} & \multirow{2}{*}{$\begin{array}{l}\text { ANOVA } \\
d f(1,84)\end{array}$} & \multirow[b]{2}{*}{$\mathrm{P}^{2} \eta$} & \multirow[b]{2}{*}{ MANOVA } & \multirow[b]{2}{*}{$P^{2} r$} \\
\hline & $M$ & $S D$ & $M$ & $S D$ & & & & \\
\hline \multicolumn{9}{|c|}{ TV viewing habits } \\
\hline Solitary viewing & 2.48 & 0.75 & 2.29 & 0.68 & 1.34 & .02 & & \\
\hline $\begin{array}{l}\text { Interactive viewing } \\
\text { with friends }\end{array}$ & 2.10 & 0.99 & 2.12 & 0.78 & 0.01 & .00 & 0.01 & .00 \\
\hline $\begin{array}{l}\text { Viewing with friends, } \\
\text { without interaction }\end{array}$ & 3.03 & 0.68 & 3.03 & 0.96 & 0.00 & .00 & & \\
\hline \multicolumn{9}{|c|}{ Identification with characters } \\
\hline $\begin{array}{l}\text { Identification with the } \\
\text { character's negative } \\
\text { behaviors }\end{array}$ & 2.85 & 1.25 & 2.73 & 1.29 & 0.18 & .00 & & \\
\hline $\begin{array}{l}\text { Positive identification } \\
\text { with the character }\end{array}$ & 3.59 & 1.01 & 4.03 & 1.13 & 3.82 & .04 & & \\
\hline \multicolumn{9}{|c|}{ Aggressive tendencies } \\
\hline $\begin{array}{l}\text { Negative reaction in } \\
\text { anger }\end{array}$ & 2.19 & 0.87 & 2.65 & 0.89 & $4.41 *$ & .06 & $3.22 *$ & .07 \\
\hline $\begin{array}{l}\text { Violent physical } \\
\text { reaction in anger }\end{array}$ & 1.48 & 0.83 & 1.66 & 0.67 & 1.11 & .01 & & \\
\hline
\end{tabular}

$* p<.05$.

A look at Table 1 reveals that no significant differences were found in viewing habits from either the overall MANOVA $(p<.05)$ or the ANOVA $(p<.05)$ for each viewing measure (solitary, with friends, and interactive). In addition, no differences were found in overall identification either positive or negative - with the characters $(p<.05)$. Only the measure for propensity toward aggression showed significant differences in the overall MANOVA for a general negative reaction $-p<.05, F(2,168)=3.22$. It was found that participants in the at-risk group had stronger negative reactions in times of anger than their normative counterparts $-p<.05, F(1,84)=4.41$, whereas there was no difference in violent physical reactions $(p<.05)$.

\section{Correlations between Viewing Habits and Identification with Favorite Characters}

The correlations between viewing habits and identification with the characters are presented in Table 2. The table shows significant positive correlations between solitary viewing and interactive viewing with friends and identification with the character $(r=.27, p<.05$ and $r=$ $.43, p<.01$, respectively). In addition, a positive relationship was found between solitary viewing and identification with the character's negative behaviors $(r=.24, p<.05)$. No relationship was found between viewing with friends and positive or negative identification, nor was a relationship 
International Journal of Child, Youth and Family Studies (2018) 9(3): 47-67

found between interactive viewing with friends and identification with the character's negative behaviors.

Table 2 Viewing Habits and Their Coefficients with Identification with the Character's Negative Behaviors and Positive Identification with the Character

\begin{tabular}{lcc}
\hline Viewing habits & $\begin{array}{c}\text { Identification with } \\
\text { negative behaviors }\end{array}$ & $\begin{array}{c}\text { Positive identification } \\
\text { with the character }\end{array}$ \\
\hline Solitary viewing & $0.24 *$ & $0.43 * *$ \\
Interactive viewing with friends & 0.06 & $0.27 *$ \\
Viewing with friends & 0.06 & 0.21 \\
\hline
\end{tabular}

$* p<.05 . * * p<.01$.

\section{Relationship between Viewing Habits and Reactions in Times of Anger}

The relationship between viewing habits and negative reactions and violent physical reactions in times of anger is presented in Table 3.

Table 3 Participant's At-Risk Status, TV Viewing Habits, Social Behavior, and Identification and Their Coefficients with Negative Reaction and Violent Reaction in Times of Anger

\begin{tabular}{|c|c|c|}
\hline Explanatory variables & $\begin{array}{l}\text { Negative reaction } \\
\text { in anger }\end{array}$ & $\begin{array}{l}\text { Violent physical reaction } \\
\text { in anger }\end{array}$ \\
\hline At-risk child & $0.25 *$ & 0.11 \\
\hline Solitary viewing & $0.29 * *$ & $0.43 * * *$ \\
\hline Interactive viewing with friends & $0.23 *$ & $0.26 *$ \\
\hline Viewing with friends & 0.15 & 0.05 \\
\hline $\begin{array}{l}\text { Identification with the character's } \\
\text { negative behaviors }\end{array}$ & $0.51 * * *$ & $0.42 * * *$ \\
\hline $\begin{array}{l}\text { Positive identification with the } \\
\text { character }\end{array}$ & $0.53 * * *$ & $0.38 * * *$ \\
\hline
\end{tabular}

The findings presented in Table 3 reveal significant positive relationships between three variables - solitary viewing, interactive viewing with friends, and positive identification with the character - and negative reaction and violent reaction. Conversely, viewing with friends is not related to a negative reaction or a violent one. The participant's at-risk status is related only to negative reactions and not to violent ones.

\section{Path Analysis Model for Television Viewing Problems by the Participant's At-Risk Status}

The path analysis model was designed to help us understand how viewing habits lead to identification with the TV characters and how negative or positive identification leads to negative and violent reactions in times of anger, with these relationships examined among both at-risk and 
normative participants. To examine the research assumptions through a full set of equations, we developed a model using path analysis based on the measures presented and examined above.

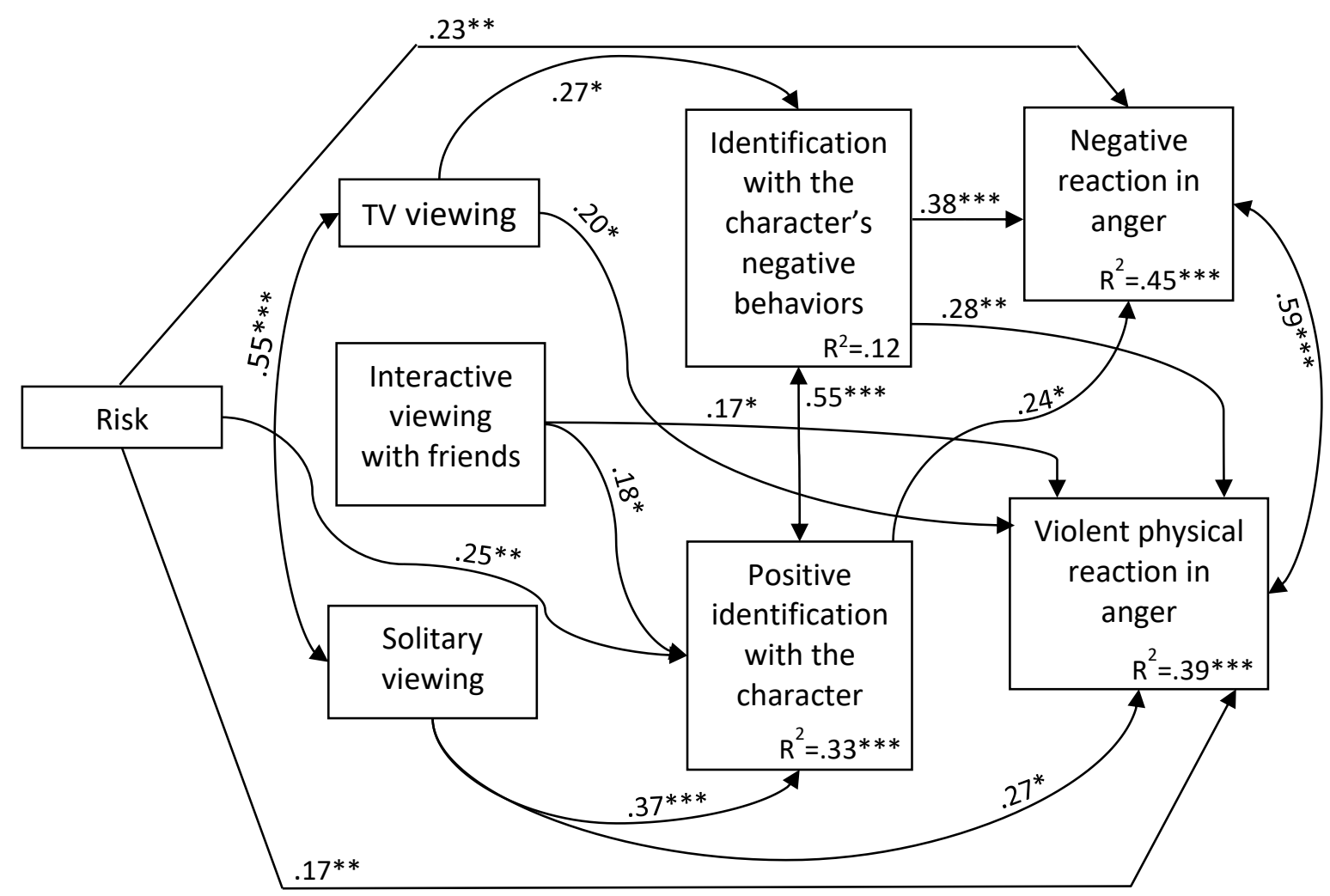

Figure 1. Path ansalysis model to describe predictive relationships among the measures studied. $* p<.05 . * * p<.01 . * * * p<.001$.

\section{The Findings According to the Model}

At-risk participants had higher positive identification with the character than their normative counterparts $(\beta=0.25, p<.01)$. In times of anger, the at-risk participants experienced greater negative reactions and violent physical reactions $(\beta=0.23, p<.01$ and $\beta=0.17, p<.01$, respectively). These results are direct, and independent of the number of hours of TV viewing or viewing habits (solitary or with friends).

It was also found that at-risk participants had greater positive identification with the character than did their normative counterparts; however, identification with the character's negative behaviors was not found to be explained based on the participant being at risk or not. In times of anger, at-risk participants had more negative reactions and more violent physical reactions than did normative participants. A relationship was found between negative reactions and violent physical ones $(r=.59, p<.001)$.

The amount of TV viewing directly explained identification with the negative behaviors of TV characters $(\beta=0.27, p<.05)$ as well as explaining violent physical reactions in anger $(\beta=$ 
International Journal of Child, Youth and Family Studies (2018) 9(3): 47-67

$0.20, p<.05)$. In other words, the more a participant watched TV, the higher the direct identification with the character's negative behaviors and the more there was a violent physical reaction to anger. The amount of TV viewing did not explain positive identification with the character.

It is thus not possible to predict the mediating variables solitary viewing, interactive viewing, and overall viewing based on a participant's belonging to the at-risk group or to the normative one. The mediating variables must be regarded independently of which group the viewer is in. The predictive level of a violent physical reaction in anger is higher with solitary viewing ( $\beta$ $=.27, p<.05)$, followed by overall viewing $(\beta=.20, p<.05)$, and finally, interactive viewing $(\beta$ $=.17, p<.05$ ), which was a moderate mediating predictor. The normative group followed the same patterns but the intensity of the reactions was different.

Solitary viewing and interactive viewing with friends explained positive identification with the character $(\beta=0.37, p<.001$ and $\beta=0.18, p<.05$, respectively), although solitary viewing better explained identification with the character than did viewing with friends. In addition, solitary viewing and interactive viewing with friends had similar positive effects on violent physical reactions in anger $(\beta=0.27, p<.05$ and $\beta=0.17, p<.05$, respectively). Again, violent physical reactions in anger were better explained among solitary viewers than among those viewing with friends and interacting with them. It was further found that the level of negative reaction in anger was explained by an increase in the level of identification with the character's negative behavior $(\beta=0.38, p<.001)$ and to a lesser degree by positive identification with the character $(\beta=0.24, p$ $<.05)$. Positive identification with the character and identification with the character's negative behaviors generated a negative reaction in anger. Conversely, a true violent physical reaction was explained only by identification with the character's negative behaviors; the intensity of the participant's negative reaction was therefore explained by this identification and not by overall positive identification with the character.

\section{Analysis of Indirect Effects}

In addition to the direct relationship presented above in the path analysis model, we wanted to demonstrate that identification with the character is a variable mediating between the viewing amount and viewing habits (solitary or with friends) and negative and violent reactions. To do so, we estimated indirect relationships as part of the path analysis.

Viewing and violent reactions were found to be significantly and positively related, yet a mediating relationship was found through identification with the character's negative behavior (ind $=0.07, p=.05$ ), so that this relationship is only partial. In addition, a full mediating relationship was found between viewing with friends and negative reaction in anger through positive identification with the character (ind $=0.09, p=.05$ ). When the amount of viewing with friends increased, identification with the character increased as did the negative reaction in anger. Similarly, there was a mediating relationship between the amount of viewing and negative reaction in anger through identification with the character's negative behaviors. The direct relationship 
International Journal of Child, Youth and Family Studies (2018) 9(3): 47-67

between the amount of viewing and the negative response was not found to be significant, but in the presence of the negative identification this relationship was found to be significant ( ind $=0.10$, $p=.03$ ). In other words, increased TV viewing strengthened the predictive relationship between identification with the character's negative behaviors and a negative reaction: when the amount of viewing increased so did identification with negative behaviors and negative reactions. This was a fully mediating relationship, because no significant direct relationship was found between the amount of viewing and a negative reaction. If it were to occur, a negative reaction to viewing would be identification with the character's negative behaviors.

Identification with the character is thus a variable that mediates between the amount of viewing and the viewing habits (solitary or with friends) and negative and violent reactions. However, while the negative reaction can be reached directly, too - in accordance with the amount of viewing - a violent reaction would only take place through the mediation of the identification variable that acts as a catalyst to the violent reaction.

\section{Discussion}

This study was an examination of the relationship between viewing habits and identification with TV characters, and the relationship between negative or positive identification and negative and violent reactions in times of anger. These relationships were examined among at-risk participants and normative ones. The findings revealed relationships between TV viewing habits and the degree of identification with the characters, and between whether or not the child was at risk (comparing at-risk participants to normative ones) and amount of viewing TV and reactions to the viewing. A path analysis model, constructed for TV viewing patterns by whether the participant was at risk, was designed to explain how viewing habits relate to identification with the characters on screen and how negative or positive identification relates to negative reactions of anger and violence among at-risk participants compared to normative participants.

\section{TV Viewing and Reactions to Viewing: Comparing At-Risk and Normative Participants}

Statistically significant differences were found in all measures of TV viewing habits regarding the participants' propensity to aggression. At-risk participants reacted with greater levels of anger than did normative ones, and had a greater tendency to react violently in anger. This violent reaction increased with the amount of TV viewing and with identification with the character's negative behaviors. The findings reveal that among at-risk viewers, violent physical reaction was related to lower socioeconomic status, amount of viewing, and negative identification with the character. Conversely, among normative participants, a better socioeconomic situation was associated with lower negative reaction, suggesting that such viewers have a greater tendency to manage anger. This finding was supported by Johnson, Cohen, Smailes, Kasen, and Brook (2002), who found a stronger relationship between a low socioeconomic status and more intense anger than among normative participants. 
International Journal of Child, Youth and Family Studies (2018) 9(3): 47-67

\section{Reactions to Viewing: Differences between At-Risk and Normative Participants}

The findings revealed that at-risk participants had more negative reactions in times of anger, and more physically violent reactions in anger than did their normative counterparts. The amount of viewing directly explains identification with a TV character's negative behaviors and also directly explains violent physical reactions in anger. In other words, the more one watches $\mathrm{TV}$, the greater the direct identification with the character's negative behaviors and the greater the chance of a violent physical reaction in anger. This is consistent with Livingstone and Das' (2010a, 2010b) findings on the relationship between a greater amount of viewing and stronger identification with the on-screen characters. The relationship between amount of viewing and negative and violent behaviors was also shown by Hough and Erwin (2010).

Bandura's $(1971,1986)$ cognitive-social learning theory can be used to explain the finding regarding the relationship between amount of viewing and identification with a TV character's negative behavior: when children and adolescents watch their favorite TV programs, the characters become "part of their lives". They love their favorite characters, identifying with them and with their motives and behaviors, and hate the characters that "annoy" their favorite characters. They feel a need to watch the program and meet the characters again and again to create a para-social interaction (a one-sided relationship) with the characters. Even when a favorite character behaves inappropriately and others condemn this behavior, these viewers defend the character, justify it, and explain the reasons for the behavior and the chain of events that led up to it. Bandura's model includes cognitive components that affect social learning: in order to learn a new behavior, the viewer must pay attention to the role model, retain the expected behavior, and retrieve this information to be able to act upon it. Therefore, viewers' cognitive skills will affect their ability to learn new behaviors through social learning.

Accordingly, the way TV role models are presented is important. Violent characters, presented in a positive and prominent way, get the viewer's focused attention, which in turn increases the chance that the behavior seen on screen will be imitated in life. Bandura $(1971,1986)$ also demonstrated that children and adolescents can see a behavior and then imitate it from memory at a later date, so that even if copying the behavior is not immediately evident after the exposure to violence, the behavior could be stored in the viewer's memory and be manifested under other circumstances. Wilson's (2011) findings are similar to Bandura's. Morgan and Shanahan (2010) found that worldviews presented on TV entrench viewers' fears. Therefore, children and adolescents who watch TV frequently, and who are exposed to levels of violence onscreen greater than in their own lives, may develop the view that the world is a dangerous and violent place.

A violent physical reaction in times of anger occurred more among solitary viewers than among those viewing in interaction with friends. It was also found that the level of negative behavior in anger was explained by the increase in level of identification with the character's negative behavior, and also, to a somewhat lesser degree, by positive identification with the 
International Journal of Child, Youth and Family Studies (2018) 9(3): 47-67

character. Both positive identification with the character and identification with the character's negative behaviors yielded a negative reaction of anger. However, a true violent physical reaction was only explained by identification with the character's negative behaviors. In other words, the intensity of the participant's negative behavior was explained by identification with the character's negative behaviors and not by an overall positive identification with the character. Similar relationships between viewing habits and negative reactions of anger and violence were found by Johnson et al. (2002) and Watkins (2009).

\section{Path Analysis Model for Television Viewing Problems by Whether a Child is At Risk}

As part of the path analysis we estimated indirect relationships, in addition to the direct relationships presented in the path analysis model. Identification with the character's negative behavior mediated the relationship between viewing and violent reaction, positive identification with the character mediated between viewing with friends and negative reaction in anger, and character's negative behaviors mediated between the amount of TV viewing and a negative reaction in anger. Haridakis and Rubin (2009) reported similar findings of direct and indirect relationships between the amount of viewing and negative and violent reactions. Conners-Burrow et al. (2011) found that watching inappropriate and violent content generated negative behaviors and even a violent reaction. Johnson et al. (2002) found that children and adolescents identify with the characters and are influenced by the characters' behavior.

\section{Conclusion}

Despite the study's limitations - the small sample size and the wide age range of the participants - important findings emerged. We found that at-risk participants react with more intense anger than do normative participants, and tend to react violently when angry, when their amount of TV viewing increases, and when they identify with a character's negative behaviors. We learned that children and adolescents watch TV programs because these programs answer various needs, some of which are not met in any other way. On the one hand, watching TV broadens children's horizons, and enables them to see various models of self-development. On the other hand, children feel that their immediate environment does not provide them with sufficient information on managing in the world, and these feelings are intensified by watching some types of programs. At-risk children and adolescents tend to choose programs that show violent behaviors, perhaps from a need to learn how to protect themselves or how to hurt others; when children identify with a character's negative behaviors in such programs, it could lead to violent reactions. The question is how can limits be placed on the amount of children and adolescents' viewing while avoiding arguments and punishment? An analysis of these findings in accordance with the UGT (Leung, 2013; McQuail, 2010; West \&Turner, 2007), which regards the viewer as a consumer whose choice of TV program is motivated by his or her needs, indicates that perhaps others in the young viewers' environment, such as parents, could help them to find other ways to meet these needs. However, to do so, parents would first have to identify the needs and then find suitable alternatives. If this could be accomplished, it would eliminate many hours of TV viewing, 
International Journal of Child, Youth and Family Studies (2018) 9(3): 47-67

and avoid the conflict and punishment often associated with reducing TV viewing. In order to identify the needs and find an appropriate answer, a dialogue must be carried out with the children and adolescents. They must be listened to, allowed to choose, and be given positive reinforcement and encouragement. The dialogue must be existential, of the type that explains to the children and adolescents that those around them are aware of their problems and needs, and regard these needs with empathy and respect. The key to success is finding a solution that will be formulated with the children and adolescents' full cooperation. 
International Journal of Child, Youth and Family Studies (2018) 9(3): 47-67

\section{References}

Abelman, R., \& Pettey, G. R. (1989). Child attributes as determinants of parental televisionviewing mediation: The role of child giftedness. Journal of Family issues, 10, 251-266. doi:10.1177/019251389010002006

Australian Communications and Media Authority. (2007). Media and communication in Australian families. Sydney, Australia: Author. Available at https://www.acma.gov.au/$\underline{\text { /media/mediacomms/Research-library-reports-old/pdf/maciaf2007_overview-pdf.pdf }}$

Alexander, A., \& Hanson, J. (2003). Taking sides: Clashing views on controversial issues in mass media and society. Guilford, CN: McGraw-Hill/Dushkin.

Anderson, C. A., \& Murphy, C. R. (2003). Violent video games and aggressive behavior in young women. Aggressive Behaviour, 29, 423-429. doi:10.1002/ab.10042

Bandura, A., (1971). Principles of behavior modification. London, UK: Holt.

Bandura, A. (1986). Social foundations of thought and action: A social cognitive theory . Englewood Cliffs, NJ: Prentice Hall.

Ben Asher, A., Zionit, Y., \& Kimchi, M. (Eds.) (2007). Children in Israel. Statistical yearbook 1992-2007 (Hebrew). Jerusalem: The Israel National Council for the Child.

Block, M. E. (1995). Development and validation of the Children's Attitudes toward Integrated Physical Education-Revised (CAIPE-R) Inventory. Adapted Physical Activity Quarterly, 12, 60-77. doi:10.1123/apaq.12.1.60

Bryant, J., \& Zillman, D. (2002). Media effects: Advances in theory and research. Mahwah, NJ: Lawrence Erlbaum Associates.

Bybee, C. R., Robinson, D., \& Turow, J. (1982). Determinants of parental guidance of children's television viewing for a special subgroup: Mass media scholars. Journal of Broadcasting, 26, 697-710. doi:10.1080/08838158209364038

Cole, T., \& Leets, L. (1999). Attachment style and intimate television viewing: Insecurely forming relationships in a para-social way. Journal of Social and Personal Relationships, 16, 495-511. doi:10.1177/0265407599164005

Comstock, G. A., \& Scharrer, E. (2007). Media and the American child. Amsterdam and Boston: Academic Press.

Conners-Burrow, N. A., McKelvey, L. M., \&. Fussell, J. J. (2011). Social outcomes associated with media viewing habits of low-income preschool children. Early Education and Development, 22, 256-273. doi:10.1080/10409289.2011.550844 
International Journal of Child, Youth and Family Studies (2018) 9(3): 47-67

Coyne, S. M., Robinson, S. L., \& Nelson, D. A. (2010). Does reality backbite? Physical, verbal, and relational aggression in reality television programs. Journal of Broadcasting \& Electronic Media, 54, 282-298. doi:10.1080/08838151003737931

Dorey, E., Roberts, V., Maddison, R., Meagher-Lundberg, P., Dixon, R., \& Ni Mhurchu, C. (2009). Children and television watching: A qualitative study of New Zealand parents' perceptions and views. Child: Care, Health and Development, 36, 414-420. doi:10.1111/j.1365-2214.2009.01031.x

Epstein, L. H., Paluch, R. A., Kilanowski, C. K., \& Raynor, H. A. (2004). The effect of reinforcement or stimulus control to reduce sedentary behavior in the treatment of pediatric obesity. Health Psychology, 23, 371-380. doi:10.1037/0278-6133.23.4.371

Evans, C. A., Jordan, A. B., \& Horner, J. (2011). Only two hours? A qualitative study of the challenges parents perceive in restricting child television time. Journal of Family Issues, 32, 1223-1244. doi:10.1177/0192513X11400558

Fowles, J. (2003). Is television harmful for children? No. In A. Alexander \& J. Hanson (Eds.), Taking sides: Clashing views on controversial issues in mass media and society (pp. 4753). Guilford, CN: McGraw-Hill/Dushkin.

Grupper, E., \& Romi, S. (Eds.). (2014). Children and adolescents at risk in Israel: Overview of the field and core issues (Vol. 1; Hebrew). Tel Aviv, Israel: MOFET Institute.

Grupper, E., \& Romi, S. (Eds.). (2015). Children and adolescents at risk in Israel: The voice of young people and issues faced by child and youth care workers (Vol. 2; Hebrew). Tel Aviv, Israel: MOFET Institute.

Hancox, R. J., Milne, B. J., \& Poulton, R. (2004). Association between child and adolescent television viewing and adult health: A longitudinal birth cohort study. Lancet, 364, 257262. doi:10.1016/S0140-6736(04)16675-0

Harel, Y., Molcho, M., \& Tilinger, A. (2003). Youth in Israel: Health, mental and social wellbeing and patterns of at-risk behavior. Summary of the findings of the Third National Study (Hebrew). Ramat-Gan, Israel: Bar-Ilan University..

Haridakis, P. M., \& Rubin, A. M. (2009). Motivation for watching television violence and viewer aggression. Mass Communication and Society, 6, 29-56. doi:10.1207/S15327825MCS0601_4

Hough, K. J., \& Erwin, P. G. (2010). Children's attitudes toward violence on television. The Journal of Psychology, 131, 411-415. doi:10.1080/00223989709603528 
International Journal of Child, Youth and Family Studies (2018) 9(3): 47-67

Jago, R., Page, A., Froberg, K., Sardinha, L. B., Klasson-Heggebø, L., \& Andersen, L. B. (2008). Screen-viewing and the home TV environment: The European Youth Heart Study. Preventive Medicine, 47, 525-529. doi:10.1016/j.ypmed.2008.07.016

Jason, L. A., \& Fries, M. (2004). Helping parents reduce children's television viewing. Research on Social Work Practice, 14, 121-131. doi:10.1177/1049731503257873

Johnson, J. G., Cohen, P., Smailes, E. M., Kasen, S., \& Brook, J. S. (2002). Television viewing and aggressive behavior during adolescence and adulthood. Science, 295, 2468-2471. doi:10.1126/science.1062929

Jordan, A. B., Hersey, J. C., McDivitt, J. A., \& Heitzler, C. D. (2006). Reducing children's television-viewing time: A qualitative study of parents and their children. Pediatrics, 118, e1303-e1310. doi:10.1542/peds.2006-0732

Leung, L. (2013). Generational differences in content generation in social media: The roles of the gratifications sought and of narcissism. Computers in Human Behavior, 29, 997-1006. doi:10.1016/j.chb.2012.12.028

Livingstone, S. (2007). Evaluating the online risks for children in Europe. Telos, 73, pp. 52-69.

Livingstone, S. (2008). Taking risky opportunities in youthful content creation: Teenagers' use of social networking sites for intimacy, privacy and self-expression. New Media \& Society, 10(3), pp. 459-477. doi:10.1177/1461444808089415

Livingstone, S. (2009). Half a century of television in the lives of our children and families. In E. Katz \& P. Scannell (Eds.), The end of television? Its impact so far (The Annals of the American Academy of Political and Social Science, Vol. 625, pp. 151-163). Thousand Oaks, CA: Sage.

Livingstone, S., \& Das, R. (2010a). Changing media, changing families: Polis media and family series. London, UK: London School of Economic, Polis.

Livingstone, S., \& Das, R. (2010b). Media, communication and information technologies in the European family: A report for the Family Platform project, funded by the European Commission. London, UK: London School of Economics.

Marshall, S. J., Biddle, S. J. H., Gorely, T., Cameron, N., \& Murdey, I. (2004). Relationships between media use, body fatness and physical activity in children and youth: A metaanalysis. International Journal of Obesity, 28, 1238-1246. doi:10.1038/sj.ijo.0802706

McQuail, D. (2010). Mass communication theory: An introduction. London, UK: Sage. 
International Journal of Child, Youth and Family Studies (2018) 9(3): 47-67

Miller, C. J., Marks, D. J., Miller, S. R., Berwid, O. G., Kera, E. C., Santra, A., \& Halperin, J. M. (2007). Brief report: Television viewing and risk for attention problems in preschool children. Journal of Pediatric Psychology 32, 448-452. doi:10.1093/jpepsy/js1035

Millwood Hargrave, A. (2007). Issues facing broadcast regulation. London, UK: Broadcasting Standards Authority.

Millwood Hargrave, A., \& Livingstone, S. (2006). Harm and offence in media content: A review of the empirical literature. Bristol, UK: Intellect Press.

Millwood Hargrave, A., \& Livingstone, S. (2009). Harm and offence in media content: A review of the evidence (2nd Rev. ed.). Bristol, UK: Intellect.

Morgan, M., \& Shanahan, J. (2010). The state of cultivation. Journal of Broadcasting \& Electronic Media, 54, 337-355. doi:10.1080/08838151003735018

Nelson, D. A., Springer, M. M., Nelson, L. J., \& Bean, N. H. (2008). Normative beliefs regarding aggression in emerging adulthood. Social Development, 17, 638-660. doi:10.1111/j.1467-9507.2007.00442.x

Nobel, G. (1976). Children in front of the small screen. London, UK: Methuen.

Office of Communications. (2006), Media Literacy Audit: Report on media literacy amongst children. London, UK: Author. Retrieved from https://www.ofcom.org.uk/_data/assets/pdf_file/0030/23898/children.pdf

Office of Communications. (2007), The Communications Market 2007. London, UK: Author. Retrieved from http://webarchive.nationalarchives.gov.uk/20160703014955/http://stakeholders.ofcom.org.u k/market-data-research/market-data/communications-market-reports/cmr07/

Office of Communications. (2010). UK adults' media literacy. London, UK: Author. Retrieved from https://www.ofcom.org.uk/research-and-data/media-literacyresearch/adults/adultmedialitreport

Potter, W. J. (2004). Theory of media literacy: A cognitive approach. Thousand Oaks, CA: Sage.

Rideout V. J, Foehr U. G, \& Roberts, D. F. (2010). Generation M2: Media in the lives of 8-18 year-olds. Menlo Park, CA: Kaiser Family Foundation.

Romi, S. (2001). Child and youth care in Israel: Trends and dilemmas in training and in therapeutic intervention programs. Journal of Child and Youth Care Work, 15-16, 171-184. 
International Journal of Child, Youth and Family Studies (2018) 9(3): 47-67

Romi, S. (2007). Child and youth care: Development and central issues. In S. Romi \& M. Schmida (Eds.), Nonformal education in a changing reality (pp. 231-249; Hebrew). Jerusalem: The Hebrew University Magnes Press.

Romi, S. (2001). Child and youth care in Israel: Trends and dilemmas in training and in therapeutic intervention programs. Journal of Child and Youth Care Work, 15-16, 171-184.

Romi, S., Savicki, V., Grupper, E., \& Caspi, R. (2007). Occupational burnout among child welfare workers: A work-setting comparison. International Journal of Child and Family Welfare. 10, (3-4), 93-109.

Schmidt Committee. (2006). Report of the Public Committee on the situation of at-risk children and adolescents (Hebrew). Retrieved from http://www.molsa.gov.il/SiteCollectionDocuments/MisradHarevacha/shmidreport2006.pdf.

United Nations. (1989). United Nations convention on the rights of the child. New York, NY: United Nations.

Valkenburg, P. M., Krcmar, M., Peeters, A. L., \& Marseille, N. M. (1999). Developing a scale to assess three styles of television mediation: "Instructive mediation," "restrictive mediation," and "social coviewing." Journal of Broadcasting \& Electronic Media, 43, 52-66. doi:10.1080/08838159909364474

Van den Bulck, J., \& Van den Bergh, B. (2000). The influence of perceived parental guidance patterns on children's media use: Gender differences and media displacement. Journal of Broadcasting \& Electronic Media, 44, 329-348. doi:10.1207/s15506878jobem4403_1

Vandewater, E. A, Bickham, D. S., \& Lee, J. H. (2006). Time well spent? Relating television use to children's free-time activities. Pediatrics, 117, e181-191. doi:10.1542/peds.2005-0812

Verona, E., Sadeh, N., Case, S. M., Reed, A., II, \& Bhattacharjee, A. (2008). Self-reported use of different forms of aggression in late adolescence and emerging adulthood. Assessment, 15, 493-510. doi:10.1177/1073191108318250

Watkins, B. (2009). Television viewing as a dominant activity of childhood: A developmental theory of television effects. Critical Studies in Mass Communication, 2, 323-337. doi:10.1080/15295038509360095

West, R., \& Turner, L. (2007). Introducing communication theory. New York, NY: McGraw Hill.

Wilson, B. (2011). Media violence and aggression in youth. In B. Wilson \& S. Calvert (Eds.), The handbook of children, media and development (pp. 237-267). Oxford, UK: WileyBlackwell. 
International Journal of Child, Youth and Family Studies (2018) 9(3): 47-67

Zilka, C. G. (2014). Empowering parents in the social media age - The Three Element Way (Hebrew). Butan-Galim.

Zilka, C. G. (2015). Social competence of children at risk: Similarities and differences among the various assessors. In E. Grupper \& S. Romi (Eds.), Children and adolescents at risk in Israel: The voice of young people and issues faced by child and youth care workers (Vol. 2., pp. 113-185; Hebrew). Tel Aviv, Israel: MOFET Institute.

Zilka, C. G. (2016). Do online friendships contribute to the social development of children and teenagers? The bright side of the picture. Journal of Humanities and Social Science, 6(8), $102-112$.

Zilka, C. G. (2017a). Children in front of screens: Alone or in company? Desktop or hybrid computer? Children's viewing and browsing habits. i-manager's Journal of Educational Technology, 14(3), 1-14. doi:10.26634/jet.14.3.13855

Zilka, C. G. (2017b). The Elements Way: Empowering parents, educators, and mentors in the age of new media. Issues in Informing Science and Information Technology, 14, 101-119. doi:10.28945/3702 